\title{
Selecting the Size of the Universal Reducer, Taking into Account its Thermal Load Capacity
}

\author{
Milan RACKOV, Siniša KUZMANOVIĆ, Zoran ANIŠIĆ
}

\begin{abstract}
Universal helical gear motors are among mechanisms that operate with a very high efficiency (about 0.98 per gear pair) $[1,2]$ and thus their thermal power capacity has not received enough attention, even in the cases when they overheat (usually at higher ambient temperature and high power motors). Therefore, it is necessary to define the thermal capacity in the catalogues of the speed reducer with a solid input shaft, as it is done by worm and helical-worm gear units which operate with much lower efficiency. Some manufacturers [3] pay necessary attention to this factor and thus enable the proper selection of gear reducers; this means they have prepared certain procedures to be undertaken if such occasion occurs, in order to overcome possible problems that may arise due to overheating the gear reducer. With this approach in the universal gear unit selection, some positive benefits can be surely achieved in the market of gear reducers, and that should not be ignored.
\end{abstract}

Keywords: thermal capacity; universal gear reducer

\section{INTRODUCTION}

Technical literature treats the problem of the thermal capacity of universal helical gear units very rarely $[4,5]$, since it is considered that they work with high efficiency and that those small thermal losses can be delivered to the surroundings with no problem. However, it is not always the case. At high temperatures of the surroundings, or when high power electric motors are used, it can happen that generated power losses cannot be given to the environment. This causes the excessive heating of the gear units (usually above $80^{\circ} \mathrm{C}$ or even $100{ }^{\circ} \mathrm{C}$ ), which can then adversely affect their performance. When choosing a universal gear unit, the catalogues of almost all gearbox manufacturers, excluding a few exceptions [3], provide a selection of gear reducers only on the basis of torque, and permissive radial and axial load of the output shaft (and the input shaft for the reducer with solid input shaft gear), while the thermal capacity is not considered. Most of gear reducer manufacturers just warn buyers in their catalogues about potential problems that may arise when a gear unit operates at higher temperatures [6] and advise them to initiate a correspondence with the manufacturer in such cases (hence, the manufacturer will choose or verify the selected gear). This procedure complicates the selection of the gear unit, though, according to them, simplifies the catalogue. However, regardless of the catalogue volume, it is necessary to define the thermal capacity and the way of its correction depending on the ambient temperature, especially for gear reducers with solid input shaft, as well as to suggest the ways to avoid the problem occurring due to the overheating of the gear unit.

When assembling the motor gear reducer, manufacturers consider this [7-9], since they connect two components, the motor and the gear unit, and are thus directly accountable for them.

\section{THE AIM OF THE RESEARCH AND PROBLEM INTERPRETATIONS}

The main objective of this paper is to highlight the importance of the thermal capacity of gear units with helical gears and the requirement for their representation in the catalogues of all gear unit manufacturers. Since the catalogues are frequently provided in the electronic form, the proposed catalogue extension would not be a special requisition for the gear unit manufacturers.

Universal gear reducers, as opposed to the special ones, include all gear units which are in their shape, connection sizes, as well as shapes and mounting positions adapted to the requirements of most machines [10]. Because of their universality, they are somewhat more complex, have more parts and require larger machining volume, so that they can meet almost all mounting requirements. However, in smaller series, they are still cheaper than special gear reducers designed for a specific purpose and having no extra parts or machining. Of course, in large producing volumes (where the term "large producing volume" depends on the size of the gear unit), it is not justified to apply the universal gear unit, mainly because of their cost and relatively large mass. Therefore, in these cases, only special gear reducers are used, for example, in construction, agriculture, machine tools and similar machines. Even then, the manufacturers of universal gear reducers always try to provide an advantage for their products in order to be able to compete successfully with special gear units. If they cannot find any advantage for it, then they simply begin to produce those special gear units, or try to produce at least some of the components for the special gear unit, for example, gears.

Today, universal gear reducers have very broad application in mechanical engineering, thanks, above all, to their simple construction, low cost, high degree of efficiency and simple and easy maintenance. They are manufactured in several variants, depending on the following $[2,10]$ :

- Mounting way with the driving machine, usually electric motor,

- Mounting way with the operating machine,

- Mounting ways,

- Mounting positions,

- Number of gear stages, and

- Special requirements (installation of direct coupling, installation of safety coupling, and mostly in gear motor, the application of regulated facilities, usually speed frequency converter, etc).

Universal gearboxes with the solid input shaft are characterized by $[1,2]$ : 
- Gear ratio - $i$

- $\quad$ Rated torque - $T_{2 N}$,

- $\quad$ Efficiency - $\eta$,

- Thermal capacity $-P_{q}$,

- Permissible overhung and thrust loads on the input shaft $-F_{R 1 \max }$ and $F_{A 1 \max }$

- Permissible overhung and thrust loads on the output shaft $-F_{R 2 \max }$ and $F_{A 2 \max }$, and

- Mass moment of inertia for gear unit - $J_{R}$,

which is all schematically shown in Fig. 1.

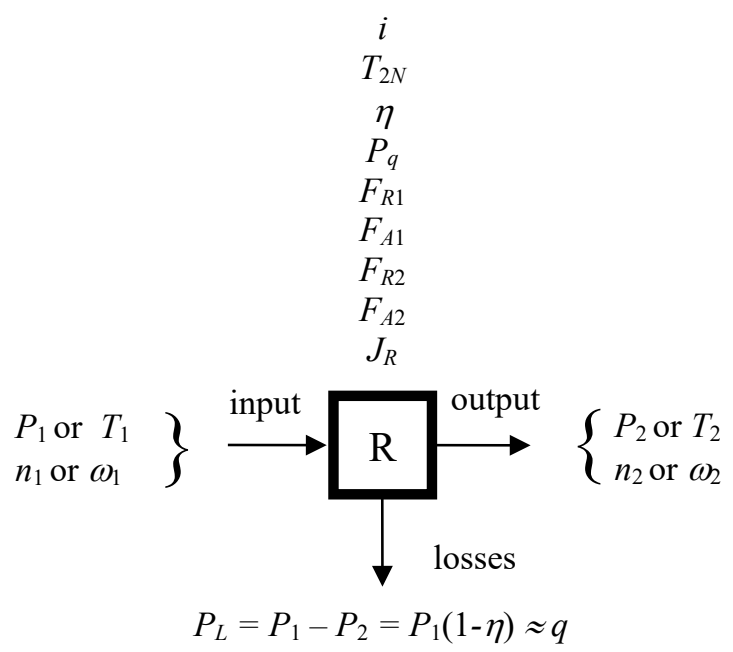

Figure 1 Schematic review of mechanical properties of universal gear reducer with solid input shaft $(\mathrm{R})$

Gear unit ratio $(i)$ is calculated through the relationship of the input speed $\left(n_{1}\right)$ to the output speed $\left(n_{2}\right)$, or the relationship of the input $\left(\omega_{1}\right)$ to the output angular velocity $\left(\omega_{2}\right)[1,2]$,

$i=\frac{n_{1}}{n_{2}}=\frac{\omega_{1}}{\omega_{2}}$

where: $n$ - rotation per minute, and $\omega$ - angular velocity $\left(\mathrm{s}^{-1}\right)$.

$\omega=\frac{\pi n}{30} \approx \frac{n}{10}=0,1 n$

Rated torque $\left(T_{2 N}\right)$ of the universal gear reducer is the highest torque that can be transmitted continuously through the output shaft with the gear unit operating under a service factor $f_{s}=1$ and with the economically acceptable maintenance costs $[1,2]$.

Rated torque $\left(T_{2 N}\right)$ is usually expressed in $\mathrm{N} \cdot \mathrm{m}$ and by definition it must be satisfied as

$T_{2 N} \geq T_{2}=\frac{P_{2}}{\omega_{2}} \approx 9550 \frac{P_{2}}{n_{2}}$

$\omega_{2}=\frac{\pi n_{2}}{30}$

where: $T_{2}$ - output torque $(\mathrm{N} \cdot \mathrm{m}), P_{2}$ - output power $(\mathrm{W}$, respectively $\mathrm{kW}), \omega_{2}$ - output angular velocity $\left(\mathrm{s}^{-1}\right)$, and $n_{2}$ - output rotation per minute.
Gear reducer efficiency $(\eta)$ demonstrates the efficiency of the gear unit and represents the relationship of the delivered power $\left(P_{2}\right)$ to the input power $\left(P_{1}\right)$ according to the following equation $[1,2]$ :

$\eta=\frac{P_{2}}{P_{1}}=\frac{P_{1}-P_{L}}{P_{1}} \leq 1$

Efficiency is always less than 1 because of the existence of losses in the gear unit $\left(P_{L}\right)$. However, if the losses can be neglected, it can be calculated that $\eta \approx 1$.

Thermal capacity of universal gear reducer $\left(P_{q}\right)$ represents the greatest input power that can be transmitted through the gear unit, under a continuous duty and an ambient temperature of $20{ }^{\circ} \mathrm{C}$, without resulting in the damage of the inner parts or the degradation of the lubricant properties. Thermal capacity is calculated from the following equation [4-6]:

$P_{L}=P_{1}(1-\eta) \approx q \leq q_{\mathrm{o}}$

where: $q$ - thermal flux obtained due to losses in the gear unit, $q_{\mathrm{o}}$ - thermal flux that can be transferred to the environment, calculated from

$q_{\mathrm{o}}=k A\left(\vartheta_{1 \max }-\vartheta_{0}\right)$

where: $k$ - coefficient of the heat transmission from the gear reducer oil to the environment, $A$ - surface area of the housing of the gear reducer that can exchange heat, $\vartheta_{1 \max }-$ temperature of oil in the gear reducer $\left(\vartheta_{1 \max }=80-90{ }^{\circ} \mathrm{C}\right)$, $\vartheta_{0}$ - temperature of the ambient where the gearbox operates $\left(\vartheta_{0}=20^{\circ} \mathrm{C}\right)$.

From the Eqs. (4) and (5), it follows that the value of the thermal power capacity is:

$P_{q} \leq \frac{q_{\mathrm{o}}}{1-\eta}=\frac{k A\left(\vartheta_{1 \max }-\vartheta_{0}\right)}{1-\eta}$

If the gearbox transmits higher power than thermal power capacity $\left(P_{q}\right)$, it leads to its overheating and thus the degradation of the lubricant properties, the unwanted increase in the dimensions of the components of the gear unit and hence its irregular operation; also, the material of gear reducer components changes its properties. If this problem occurs during the design $\left(q>q_{\mathrm{o}}\right)$, it should be adjusted by increasing the surface area of the gearbox housing (usually by placing the ribs), or even by additional cooling (mounting the fan and forced air convection around the housing, or installing the oil pump and the heat exchanger to cool the oil in the gear unit). If the problem is established when selecting a gear reducer, then the gearbox oil should be cooled in the housing, or a larger gearbox should be selected, which is usually a more expensive solution. This problem typically occurs when large power is transferred, or at high outside temperatures, or when there are large losses in the gear unit (which is usually not the case for the helical gear unit).

Permissible overhung and thrust loads on the input and output shaft of the universal gear reducer $\left(F_{R 1}, F_{A 1}\right.$, $\left.F_{R 2}, F_{A 2}\right)$ are the largest radial and axial forces that permanently act onto the input and output shaft of the 
universal gear reducer, with a steady load compatible with the bearing and shaft capacity, and with the capacity of screws and circlips $[1,5]$.

Mass moment of inertia for the gear unit $\left(J_{R}\right)$ represents the moment of inertia of the rotating parts of the universal gear reducer. Its value is needed for a precise definition of the necessary motor power, i.e. for the exact definition of the initial torque, as well as in defining the moment of braking.

Universal gear units are characterized by a series of other characteristics, such as:

- Shaft height,

- Specific mounting dimensions,

- Mounting ways,

- Mounting position,

- Oil level in the gear reducer,

- Weight of the gear unit,

- Operating temperature,

- Operating life,

- Noise level of gear units,

- Vibration level of gear units,

- Vibration level that gearboxes can be exposed to during operation (according to DIN 4150 and AGMA 6000-B96),

- Circumferential backlash in gear units, etc.

All these characteristics largely determine the quality and the cost of helical gear units, as well as the possibility of their application $[7,10]$.

Universal gear reducer can be assembled with or without the electric motor. If it is assembled with the electric motor, it can be special, the so-called reducer motor, or the standard (IEC) motor $[1,2]$. What type of the electric motor will be used depends on the attitude of the manufacturer's company, as well as the specific requirements of customers.

The basic features of the universal gearmotor reducer are:

- Rated power of the driving motor $-P_{e m}$,

- Output speed - $n_{2}$,

- Permissible value of the service factor $-f_{B D}$, and

- Permissible overhung and thrust force on the output shaft $-F_{R 2}$ and $F_{A 2}$,

which is schematically depicted in Fig. 2.

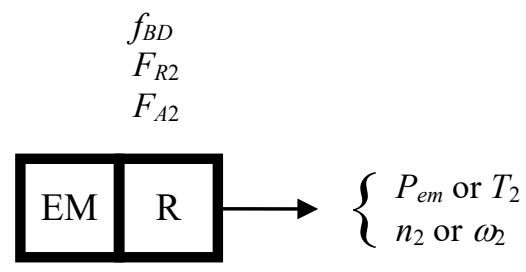

Figure 2 Schematic review of mechanical properties of the gearmotor, electric motor (EM) and gear unit (R)

Universal gearmotor that works with the high efficiency usually only has the specified power of the electric motor $\left(P_{e m}\right)$, while for other cases, the output torque $\left(T_{2}\right)$ must be obtained.

$$
T_{2}=9550 \frac{P_{e m}}{n_{2}} \eta
$$

where: $\eta$ - gear motor efficiency, $n_{2}$ - speed of output shaft.

Output speed $\left(n_{2}\right)$ value is calculated from the relationship of the input speed $n_{e m}$ to the gear ratio $i$, as per the following equation:

$n_{2}=\frac{n_{e m}}{i}$

As a rule, only standardized (rounded) input speeds are listed according to the standard line R20, which can be different from the actual number of revolutions up to $\pm 5 \%$.

Permissible value of service factor $\left(f_{B D}\right)$ represents the relationship of the rated torque $\left(T_{2 N}\right)$ with the actual output torque $\left(T_{2}\right)$, according to the following equation $[2,3]$ :

$$
f_{B D}=\frac{T_{2 N}}{T_{2}}
$$

and it defines how much the hard gear reducer can be loaded.

The previous Eq. (9) is obtained from the basic condition which the gear reducer should satisfy in order to operate successfully:

$T_{2 N} \geq T_{2} f_{B}$

where: $f_{B}$ - service factor that describes all service duties and operating irregularities of the gear reducer. The service factor is determined as the product of many factors taken into account: the type of the driving machine, daily operating time, the starting frequency per one hour, and sometimes, the effective load during an hour (so-called ED factor), ambient temperature, and desired lifetime of the gear reducer. Gear unit manufacturers usually calculate for their products to be used for 5 years; hence, their operating time is 10,000 hours. This operating time is obtained by multiplying the 5 years with 50 working weeks and with 40 hours per week.

Permissible value of the service factor $\left(f_{B D}\right)$ is obtained from the Eq. (10) and the following condition must be satisfied:

$$
f_{B D}=\frac{T_{2 N}}{T_{2}} \geq f_{B}
$$

This is an important condition for selecting and adopting gear reducers.

Permissible overhung and thrust loads on the output shaft of the gearmotor $\left(F_{R 2}, F_{A 2}\right)$ are the largest radial and axial forces that permanently act onto the output shaft of the gearmotor, with a steady load compatible with the bearing and shaft capacity, and with the capacity of screws and circlips [5].

If the gearboxes are delivered without the electric motor, they can be equipped with an input shaft assembly or with the adapter for mounting IEC motors.

Large manufacturers usually use special reducer motors, which are characterized by special flanges, special diameters of motor shafts, stronger bearings and better sealing solutions. They have a number of advantages, such as easier, cheaper and more compact design, the possibility of achieving higher gear ratios, greater permitted force of the 
motor shaft and better tightness. Since they are buying large quantities of such motors, they get them quickly and almost at a price of standard motors, so that this procedure is completely payable to gear reducer manufacturers. In addition, these manufacturers usually have their own factory of electric motors, so that they practically do not have any problems $[1,2,10]$.

Small and medium manufacturers of gear units usually use standard IEC motors, although it is not the rule, mainly because of the lower cost and short delivery time; all the benefits of special motors they try to compensate by a suitable way of installing the motor onto the gear unit. Since it is difficult to make up for a lot of advantages of special motors, in practice there are different construction solutions for installing the gear unit with standard IEC motors; they can be connected directly, or with the IEC motors interface, with the gear unit housing.

Gear units with standard IEC motors are delivered by large manufacturers, who use special geared motors, only when customers require it, for example, when a customer personally wants to install motors on the purchased gear units. It is usually the case when they think they can do cheaper or faster service of their motors or in the case of the export of gear units. In the latter case, usually there are factories of electric motors, and the country imposes large taxes on motors in order to protect their products from foreign competition, and discourage the customers to buy imported electric motors. Hence, they buy gear units with the adapter for the IEC motor, which allows them much easier and more secure IEC motor mounting; it can also mean that there is no possibility to install the motor incorrectly $[2,10]$.

\section{SELECTION OF THE GEAR REDUCER}

Selection of the size and the type of the gear reducer is performed after choosing the type of gearing inside the gear unit [1]:

- Helical gear unit,

- Bevel gear unit,

- Helical-bevel gear unit,

- Worm gear unit,

- Helical-worm gear unit,

- Unit with special gearing, etc.

The selection of gear units depends on application demands (primarily the available space for installation, efficiency, self-locking requirement, demand for peace and quiet performance, etc.) and also on the installation possibility of the gear unit (the mounting position) $[2,11]$ :

- Foot-mounted,

- B14 flange-mounted,

- B5 flange-mounted,

- B5 flange-mounted type with the extended bearing hub,

- Foot and B5 flange-mounted type,

- Type with the hollow shaft,

- B5 flange-mounted type and hollow shaft.

It should also be noted that the installation position has to be defined (the same as for an electric motor):

- Horizontal with the feet down,

- Horizontal with the feet on the side,

- Horizontal with the feet up,

- Vertical with the output shaft down,
- Vertical with the output shaft up, etc.

In most installation positions, there are gear units flangemounted, foot-mounted, foot and flange-mounted, then with hollow shaft and flange-mounted with hollow shaft [11]. The decisive factor is the mounting position, since it defines the position of holes to pour lubricant, oil level plug, oil drain plug and breather valve. Breather valve is usually used for pouring the oil, although this is not the rule. Breather valve is a special bolt with a hole through where the air is released when the gear unit is heated to prevent the high pressure in the housing that would cause lubricant extrusion, and through which the air enters when gear unit is cooling. These valves are made in different versions.

For gearmotors, the position of the terminal box must be defined, as well as the position of the cable entry into the electric motor, in order to allow a simpler and more elegant connection to the electric power network.

After defining all these parameters, the next step is to adopt the smallest gear unit that meets the following requirement:

$T_{2 N} \geq f_{B} T_{2}$ i.e. $f_{B D} \geq f_{B}$

for the required value of the gear ratio, which should not be more than $\pm 5 \%$ from the required value. If it is not possible to perform this solution, the solution in other value of the gear ratio or other (larger) size of the gear unit should be found. For the gearmotor, the permissible value of the service factor $f_{B D}=T_{2 N} / T_{2}$ is provided in manufacturers' catalogues, for each power and rotation number individually for each reducer $[3,12,13]$.

With the permitted torque, the selected gear unit also has to satisfy the permissive value of the load capacity at the output shaft. However, the gear unit with the solid input shaft has to permit both values of the load capacity at the input and output shaft, as well as the thermal capacity, i.e. the following requirements have to be satisfied $[2,5]$ :

$$
\begin{aligned}
& F_{\mathrm{R} 1} \leq F_{\mathrm{R} 1 \max } \\
& F_{A 1} \leq F_{A 1 \max } \\
& F_{R 2} \leq F_{R 2 \max } \\
& F_{A 2} \leq F_{A 2 \max } \\
& P_{1} \leq P_{q}
\end{aligned}
$$

where gear unit manufacturers determine permissible loading values in their catalogues, while the actual values are calculated according to the equations from mechanics and machine elements. In the case of the approximate calculation, the radial force value can be obtained considering the tangential force $\left(F_{t}\right)$ according to the following equation:

$$
F_{r}=F_{t} f_{z}
$$

where: $F_{t}$ - tangential force on the element mounted onto the shaft end $\left(F_{t}=2 T / d\right.$, where $T$ - torque on the transmission element, $d$ - mean diameter on the installed transmission element) and $f_{z}$ - factor of the transmission element, for:

gears with $z<17 f_{z}=1.15$ 
sprocket with $z<13 f_{z}=1.4$

sprocket with $z<20 f_{z}=1.25$

narrow V-belt pulleys $f_{z}=1.75$

flat-belt pulleys $f_{z}=2.5$

If some of these conditions are not satisfied, the solution should be found in the frame of the nearest gear ratios, and after that, usually within the first larger size of the gear unit.

If the gearmotor is selected, it should be chosen for the required power $(P)$ and the rotation number $(n)$, satisfying the following requirements:

$$
\begin{aligned}
& f_{B} \leq f_{B D} \\
& F_{R 2} \leq F_{R 2 \text { max }} \\
& F_{A 2} \leq F_{A 2 \max } \\
& P_{1} \leq P_{q}
\end{aligned}
$$

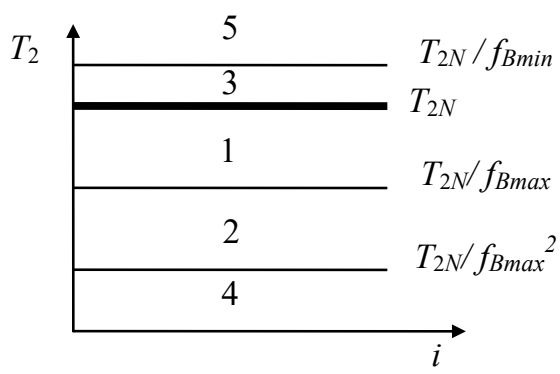

Figure 3 Schematic review of the application field of gear units according to torque values: 1 - the main area; 2 - the additional area; 3 - critical area (used only for short drives); 4 - the area where the reducer is oversized; and 5 - critical area where the breakdown of the reducer happens immediately

It follows that the basic element determining the selection of the gearbox size is its operating regime, corresponding to the service factor, which takes into account all irregularities occurring during operation. This means that the gear unit usually operates in the area of

$T_{2 N} \geq T_{2} \geq \frac{T_{2 N}}{f_{B \max }}$

which is schematically demonstrated in Fig. 3.

The area under $T_{2 N} / f_{\text {Bmax }}$ corresponds to oversized gear units and it should conceptually and constructionally provide one smaller size of the gear unit, i.e. the shift between nearby sizes of gear units must be

$$
T_{2 N(n+1)}=f_{B \max } T_{2 N(n)}
$$

so that

$$
T_{2 N(n+1)}=q_{T} T_{2 N(n)}
$$

where: $q_{T}=2=f_{B \max }-$ factor of torque increase. Most of manufacturers respect this torque transition, because it is in the theory of standard numbers $q_{T}=2=q_{L}{ }^{3}=1.25^{3}$ which corresponds to the increase in linear measures by standard series R10 or R20/2[1, 2].

However, one should consider that the gear unit could be used outside its main application $\left(T_{2 N} \geq T_{2} \geq T_{2 N} / f_{B \max }\right)$ for the transmission of smaller torques when the first smaller gear unit cannot be satisfied (the area $T_{2 N} / f_{B \max } \geq T_{2} \geq$ $\left.T_{2 N} / f_{B \max }^{2}\right)$. The gear unit is usually not used in the area under $T_{2 N} / f_{B \text { max }}{ }^{2}$ because it is so oversized; in this part, the first smaller size is used, if it exists. If there is no smaller size, the oversized gear unit can be used with certainty though not economically. The gear unit should not be loaded with the torque higher than $T_{2 N}$. However, in the case of the shortterm operation and steady loads, it can be shortly overloaded (critical area $T_{2 N} / f_{B \min } \geq T_{2} \geq T_{2 N}$ ). Therefore, this gear unit will be damaged prematurely, i.e. it will have a shorter operating life. Nevertheless, due to the low intensity of use, it will reach the exploitation life (usually about 5 years) which can be considered as quite satisfactory for standard (universal) gear units. This overload is possible from the standpoint of the safety of individual elements because the minimum value of the service factor is usually $f_{B \min }=0.8$, and the maximum load is

$T_{\max }=\frac{T_{2 N}}{f_{B \text { min }}}=\frac{T_{2 N}}{0.8}=1.25 T_{2 N}$

This is less than the critical load, obtained due to the minimal factor of safety (usually $S_{\min }=1.3$ ); hence, that load does not damage the structure, though it does not guarantee a long life or complete security. However, it can operate satisfactorily considering the reserve that it usually occurs when selecting a stronger electric motor than necessary. In that case, the permissible service factor is calculated $\left(f_{B D}=T_{2 N} / T_{2}\right)$ and the reserve occurs when selecting the gear unit, because the condition $f_{B D} \geq f_{B}$ must be satisfied $[2,3,12,13]$.

The standard recommends that the nominal torque of gear units is adopted from the numbers of a standard line R20. Most manufacturers consider this; however, later, when defining the actual load capacity for certain gear ratios, they usually adjust the actual value. As a consequence, this value is usually different from the designed (standard) value which provides more economical use of the gear unit.

When defining the load capacity of gear units, manufacturers take into consideration the competition, i.e. technical characteristics of their gear units. It is economically reasonable due to the possibility of displacement, since the adjustment of the gear unit load capacity with its axis heights is not defined as standard.

When defining the basic sizes of the electric motor which will be installed onto gear units, gear reducer manufacturers take into account the possibility of mounting these two components; first of all, they consider geometric characteristics (axis height), then the available power and revolution numbers according to which the transferred torque is calculated, as well as the thermal capacity. When defining the rated powers, only four-pole electric motors are considered, since they have the best initial characteristics (higher torque and relatively slow starting point, with no high shocks) and their special advantage is in their availability, with short delivery times and low cost. Threephase AC electric motors are commonly used for driving gear reducers; on special request, other motors can be delivered though with a higher price. Actual values of the nominal torque for the particular size of gear units are defined on the basis of the motor power (torque), limit value of gear ratios, possible nominal torque value, and the socalled diagram of power (Fig. 4). Particular values of gear 
ratios, the load capacity for individual gear ratio and the possibility of installing (i.e. the possibility of installing certain motors for different gear ratios) are settled during the design of each gear unit individually.

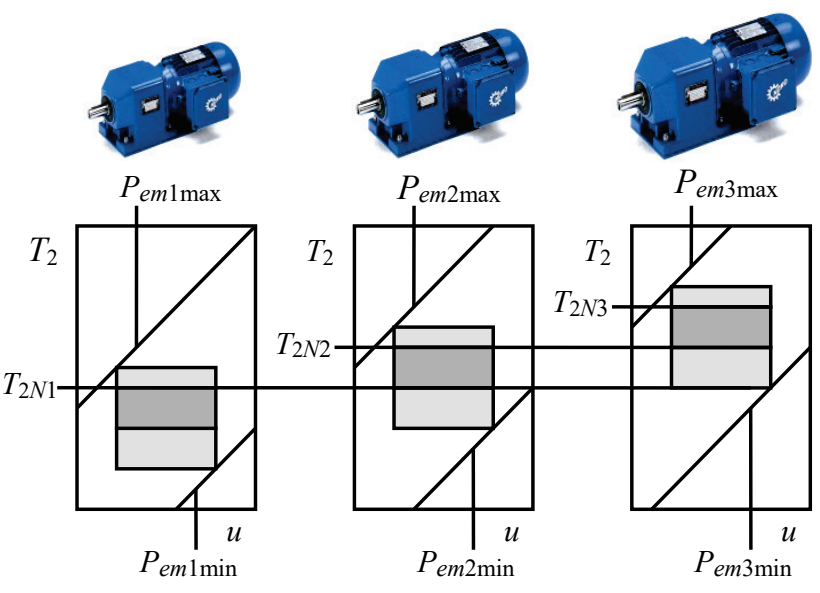

Figure 4 Schematic review of torque and gear ratio areas that are covered by particular gear unit sizes, for example, with one stage reducer

The number of different gear ratios (usually the numbers from standard series R20) depends on the selected solution of the installing motor with the gear unit, although it tends to be less output, large and expensive gears and more input, smaller and not so expensive gears. In the case that the pinion is not directly placed on the shaft of the electric motor, it is not necessary to provide the pinion (for every gear ratio) with different openings, which results in reducing the number of pinions.

\section{HEATING OF THE GEAR UNIT}

Regardless the power (size) of electric motors, all losses occurring in the gear unit have to be transferred to the surroundings, Eq. (4). It should be remembered that the heating rate of the gearbox depends on the operating regime, its duration, input power, thermal inertia of the gear reducer mass and the selected method of cooling.

After measuring the temperature of the universal gear reducer with the shaft height $h=90 \mathrm{~mm}$, it can be concluded that the tested gear unit reaches the operating temperature relatively quickly, which does not change any further since the reducer operates with a constant load of $T_{2}=164 \mathrm{~N} \cdot \mathrm{m}$, i.e. with the constant input power.

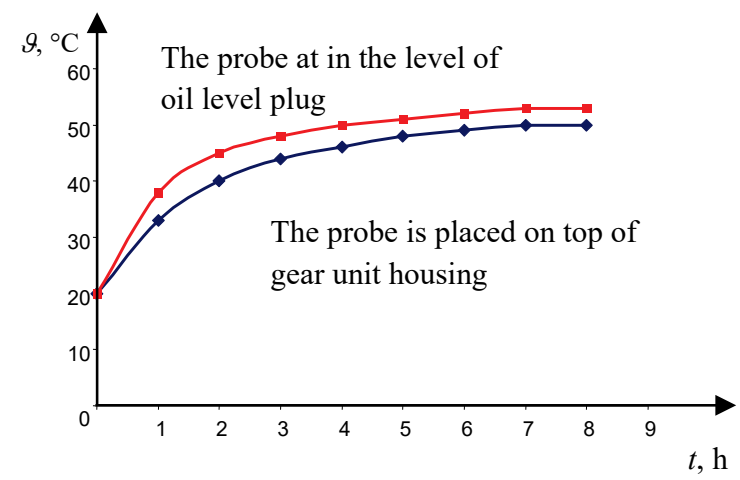

Figure $\mathbf{5}$ Graphic review of the temperature line of housing of the two-stage gear unit with the shaft height $h=90 \mathrm{~mm}$, during nine hours of operation, measured in the points of oil level and top of housing $\left(T_{2}=164 \mathrm{~N} \cdot \mathrm{m}, n_{2}=161.5 \mathrm{~min}^{-1}\right)$
The combined thermometer, anemometer, compact light meter and humidity meter by the manufacturer SPERO Scientific, type 850070, has been used for measuring the temperature.

The thermometer probe was placed on the external side of the housing of the gear unit at the level of the oil level plug and on top of housing in order to obtain the actual temperature of the gear unit housing. The temperature was read every hour and, based on it, the diagram (Fig. 5) was created. The ambient temperature in the test station was $\vartheta_{0}$ $=20{ }^{\circ} \mathrm{C}$ and it was constant during the measuring due to the air conditioner.

Based on the measured data, the thermal load capacity of the tested gear unit can be calculated in this way $[5,14]$ :

$$
P_{q}=\frac{q_{\mathrm{o}}}{1-\eta}=\frac{k A\left(\vartheta_{1 \max }-\vartheta_{0}\right)}{1-\eta}=\frac{T_{2} n_{2}}{9550 \eta}
$$

From the given equation, the value of products of the coefficient of heat transmission and the surface area of housing $(k A)$ can be calculated and, based on it, the value of the thermal power capacity $P_{q}=5.42 \mathrm{~kW}$ for the temperature of $\vartheta=80^{\circ} \mathrm{C}$.

It is also necessary to consider that the thermal capacity has different values, depending on the ambient temperature and the number of gear stages and sometimes on the shape and position of the gear unit mounting. Those values can be sorted as a table or a diagram (Fig. 6).

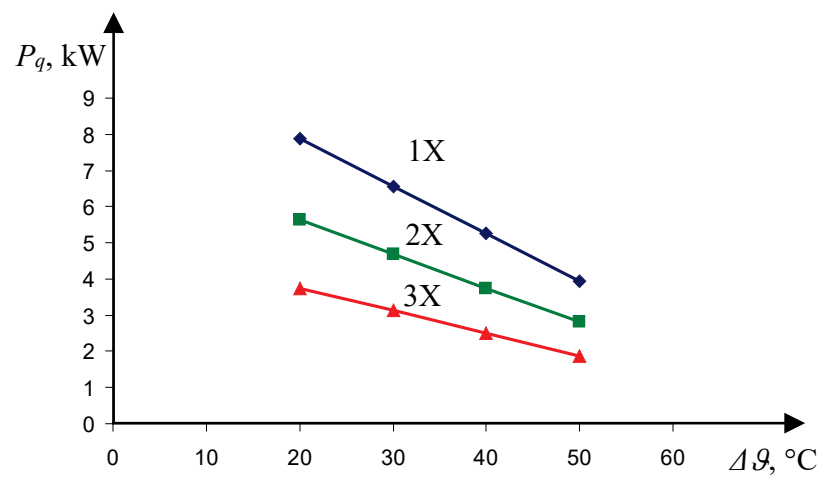

Figure 6 Schematic review of heat capacity (values obtained by calculation) for individual sizes, gear ratios and mounting positions $(1 \mathrm{x}-$ single stage, $2 \mathrm{x}-\mathrm{two}$ stage and $3 \mathrm{x}$ - three-stage gear unit) with the shaft height $h=90 \mathrm{~mm}$

Thermal power capacity is slightly different for the gearmotor and the gear unit without the installed motor, because the fan of the electric motor of the gearmotor provides some greater air circulation and thus better cooling of the reducer. Nevertheless, due to the heating of the electric motor, the gearbox is subjected to the somewhat greater heating from the motor. Sometimes these cooling and heating quantities can be cancelled, and sometimes, unfortunately they cannot, so they should be separately shown in the diagram (or table).

The attempts to reduce the costs of the production of electric motors are directed towards minimizing the material consumption; it can cause the motor to be more heated, demanding the insulation material of the class " $F$ " to be installed in motors nowadays (allowing heating up to $150{ }^{\circ} \mathrm{C}$ ). The motor fan does not allow reaching this temperature; however, it is certain that the high 
temperature of the motor leads to more heating of the gear unit, especially if the motor has a higher starting frequency and particularly when it comes to braking which further heats the motor and the gear unit.

The operating regime also has a great influence on heating the gear unit or the gearmotor. For example, the load capacity, the duration of operation and the number of startings can strongly affect the heating of the gearbox and thus the actual load of the gear reducer. Different combinations of these parameters have a great influence on heating. Calculating their influence is quite complex and cannot be accurately described by mathematics, though very accurate values can be obtained by measuring.

The influence of the operating regime of helical gear units has to be considered in the same way as the operating regime of worm gear units.

The value of thermal capacity decreases with the increase in the ambient temperature. Thermal capacity will be larger by reducing the ambient temperature and by operating with interruptions, but only to a limit defined by the mechanical strength of the material that the components are made of.

\section{DESCRIPTION OF WAYS FOR SOLVING THE PROBLEM}

When selecting the helical gear unit, among other conditions, the following has to be satisfied:

$$
P_{1} \leq P_{q}
$$

Gear reducer manufacturers consider this condition in their catalogues and account that the normal ambient temperature is $\vartheta_{0}=20^{\circ} \mathrm{C}$. If the gear unit operates in higher ambient temperatures, the manufacturer invites customers to contact them with a request to select or check the selected gear reducer. This procedure is included for practical reasons, so that the producer does not have any cost of possible damage.

When selecting the gear unit without the mounted motor, the composition of the drive unit is left to the customer who sometimes does not care about this factor. However, the manufacturer invites customers to contact them if the ambient temperature is increased. It seems that it would be much easier to create a little expansion of the catalogue and make all data available to the customers [3], enabling a simpler and more regular selection of the gear reducer.

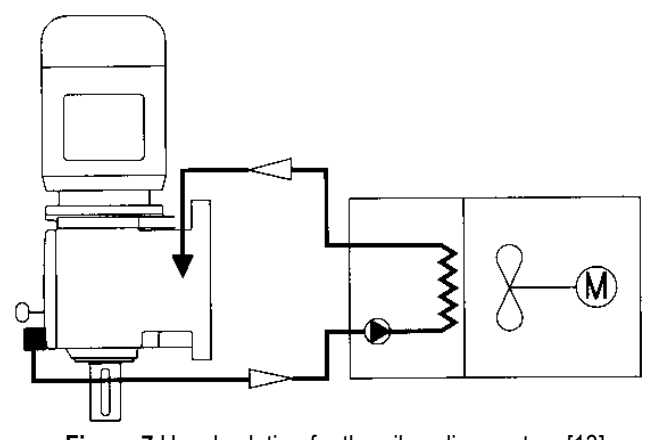

Figure 7 Usual solution for the oil cooling system [13]
So, the selection of the gear unit is based on its load capacity $\left(T_{2 N}\right)$ and permissible radial $\left(F_{R 1 \max }\right)$ and axial $\left(F_{A 1 \max }\right)$ load acting on the input shaft only for the reducer without the installed motor, and on the permissible radial $\left(F_{R 2 \max }\right)$ and axial $\left(F_{A 2 \max }\right)$ force acting on the output shaft (for both types of reducer), while the thermal capacity is not emphasized, and it should be required. The proper selection of gear reducers will be possible only by satisfying the condition $P_{1} \leq P_{q}$.

In the case that the condition is not satisfied (Eq. (21)), it is necessary to adopt a larger (stronger) gearbox, with a larger surface area participating in the exchange of heat, or it is necessary to use the system for oil cooling. For smaller sizes of gear reducers, it is cheaper to select a larger gearbox, while in the case of medium and large size reducers, it is rational to use the oil cooling system [15]. The system consists of a filter, circulating pumps, overflow and several classic valves, piping and heat exchanger with a fan and electric motors (Fig. 7). Certain manufacturers offer these components in their catalogues as standard components which can be ordered together with the gearbox, so that the problem of possible heating is eliminated in the start.

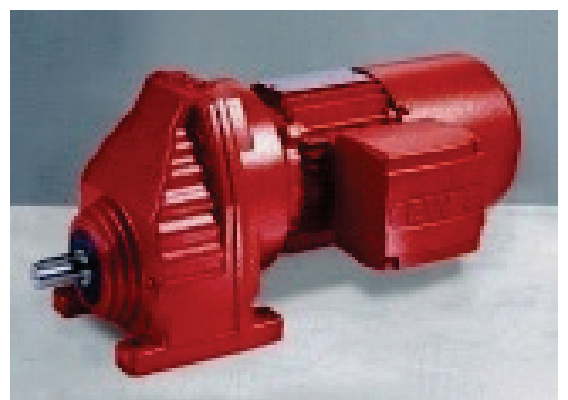

Figure 8 Typical detail of the helical gearmotor with placed ribs in order to make the housing stronger and increase the surface area of housing which transmits the heat with the environment (SEW)

Gear reducer manufacturers are aware of this problem and take into account the thermal capacity of their gearboxes, trying to increase it. They usually manage this by placing ribs on the surface of the housing of the gear unit (Fig. 8) or by increasing the coefficient of heat transmission and defining such forms of housing that will provide better air circulation around it, driven by a fan of an electric motor (this is only applied for the geared motor).

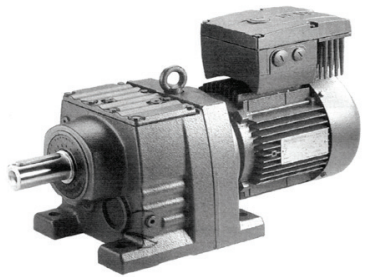

1

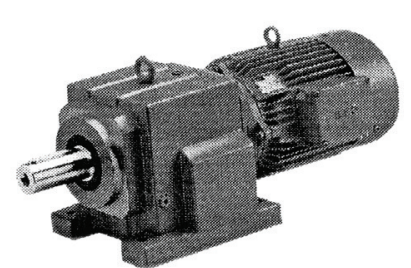

2
Figure 9 The characteristic shape of the gearmotor housing that provides better air circulation and thus better dissipation of heat (1) SEW and (2) SIEMENS FLENDER

Having these design solutions, the gear reducer becomes less sensitive to the increasing in the ambient temperature; however, this is applicable only up to a certain limit. 


\section{CONCLUSION}

In the process of choosing helical gear reducers, the consideration of thermal power capacity can result beneficially in the proper selection of gear units, thus preventing the possibility of overheating. Manufacturers of reducers take into account the proper selection of the gearmotor; on the other hand, the customers of the helical gear units without the installed motor choose a motor and a gearbox typically without paying enough attention to this problem. If the ambient temperature is higher (where it is not emphasized what the higher temperature is), customers are called to contact the manufacturer in order to make the proper selection or check the selected gear unit. Making additional instructions in the catalogue of universal helical gear units, i.e. specifying the values of the thermal capacity in the function of the ambient temperature could enable selection of appropriate gear reducer and avoid all irregularities that can occur due to the overheating of the gearbox. This catalogue expansion should not represent a problem for gear reducer manufacturers since the catalogues are usually provided in the electronic form; thus, the increase of "printing" costs would be extremely low.

Providing proper instructions related to the thermal power capacity can help the customers who use these helical gear units. Knowing the accurate data about the ambient temperature, the duration of operation and the number of startings offers the customers much easier way to adopt the proper reducer for their use, without overpaying it, as it is usually the case when the reducer is chosen by the manufacturer.

\section{REFERENCES}

[1] Kuzmanović, S. (2009). Universal Helical Gear Reducers. Faculty of Technical Sciences, Novi Sad.

[2] Kuzmanović, S. \& Rackov, M. (2009). Development Tendencies of Universal Gear Reducers. Proceedings of the $3^{r d}$ International Conference "Power Transmissions 2009", Ed.: A. Mihailidis / Kallithea, Greece, 145-148.

[3] Siemens, MOTOX Geared Motors, Catalogue D87.1-2014

[4] Nazifi, K. \& Predki, W. (2014). Micropitting of Large Gearboxes Influence of Geometry and Operating Conditions. Gear Technology, September/October, 50-54.

[5] Barišić, B., Kuzmanović, S., \& Rackov, M. (2011). Effect of External Loads at the Output Shaft End of Universal Worm Gear Reducer on Its Thermal Capacity. Proceedings of the $7^{\text {th }}$ International Scientific Conference Reserch and Development of Mechanical Elements and Systems - IRMES 2011 / Zlatibor, University of Niš, Mechanical Engineering Faculty, Serbia, 535-540.

[6] Frost, R. B. \& Cross, T. R. (1991). Full-Load Testing of Large Gearboxes Using Closed-Loop Power Circulation. Gear Technology, September/October, 35-38.

[7] Zadnik, Ž., Karakašić, M., Kljajin, M., \& Duhovnik, J. (2009). Function and functionality in the conceptual design process. Strojniški vestnik - Journal of Mechanical Engineering, 55(7-8), 455-471.

[8] Anišić, Z., Ćosić, I., \& Kuzmanović, S. (2004). The Influence of Customization and Requests for Prompt Delivery on Gearmotor Design Concept. Proceedings of Tools' 2004 Conference / Kočovce, Slovakia, 68-74.
[9] Anišić, Z. \& Krsmanović, C. (2008). Assembly Initiated Production as a Prerequisite for Mass Customization and Effective Manufacturing. Strojniški vestnik - Journal of Mechanical Engineering, 54(9), 607-618.

[10] Schultz, C. D. (2004). A Key to Economical Gearbox Purchases. Gear Technology, November/December, 18-21.

[11] Kuzmanović, S., Ianici, S., \& Rackov, M. (2010). Analysis of Typical Method of Connection of Electric Motor and Gear Unit in the Frame of Universal Motor Gear Reducers. Machine Design, 2(1), 141-146.

[12] SEW Eurodrive, Catalogue - Gear Units, Edition 06/201616997611

[13] NORD Drivesystems, Standard Helical Gearboxes, G 2012 , Getriebebau Nord, Hamburg

[14] Topić, R. \& Kuzmanović, S. (2006). Temperature Influence on Shape of Machine Constructions. Proceedings of the Fourth Symposium about Constructing, Shaping and Design, KOD - 2006 / Palić, Serbia, 121-126.

[15] McGuinn, J. (2008). Gearbox Speed Reducer Helps Fan Technology for "Greener" Jet Fuel Efficiency. Gear Technology, August, 18-22.

\section{Contact information:}

Milan RACKOV, PhD

Faculty of Technical Sciences,

University of Novi Sad,

Trg Dositeja Obradovića 6

21000 Novi Sad, Serbia

E-mail: racmil@uns.ac.rs

\section{Siniša KUZMANOVIĆ, PhD}

Faculty of Technical Sciences,

University of Novi Sad,

Trg Dositeja Obradovića 6

21000 Novi Sad, Serbia

E-mail: kuzman@uns.ac.rs

\section{Zoran ANIŠIĆ, PhD}

Faculty of Technical Sciences,

University of Novi Sad,

Trg Dositeja Obradovića 6

21000 Novi Sad, Serbia

E-mail: anisic@uns.ac.rs 